\title{
Descripción histológica de la piel de la rana gigante del Titicaca (Telmatobius culeus)
}

\author{
Histological DESCRIPTION OF THE SKIN OF THE TitiCACA WATER FROG \\ (Telmatobius culeus)
}

\author{
Priscila Andrade ${ }^{1}$, Roberto Elías P., ${ }^{1,2}$, Ricardo Grandez R. ${ }^{1}$, Javier Mamani P. ${ }^{1}$
}

\section{Resumen}

El estudio describe las características morfológicas e histoquímicas de la piel de la rana gigante del lago Titicaca Telmatobius culeus. Se tomaron muestras de piel de seis zonas corporales de 20 especímenes. Las técnicas histológicas que se emplearon fueron con la tinción de Hematoxilina-Eosina (HE) para describir las características morfológicas de la piel; Alcian Blue $\mathrm{pH} 1.0$ para la detección de muco-substancias sulfatadas y a pH 2.5 para detectar las muco-substancias ácidas; Ácido Periódico de Schiff (PAS) para mucopolisacáridos neutros y ácidos (hidroxilo); Azul de Toluidina para la identificación de ácidos sulfatados, carboxilados y fosfatados, además de observar la presencia de metacromacia, que indica la presencia de ácidos aniónicos o polianiónicos; y Tricrómico de Mallory para la descripción de tejido conectivo. Las muestras de la piel guardaron similitud con las características morfológicas de otros anfibios descritas en estudios previos: las regiones dorsal y parotídea poseen el mayor espesor de dermis y los dos tipos de glándulas encontradas denotan ser de naturaleza heterogénea, serosas y mucosas.

Palabras clave: Telmatobius culeus; piel; glándulas; histología; histoquímica

\section{ABSTRACT}

This study describes the morphological and histochemical characteristics of the skin of the Titicaca water frog Telmatobius culeus. Skin samples were taken from six body regions of 20 specimens. The histological techniques used were with Hematoxylin-Eosin staining (HE) to describe the morphological characteristics of the skin; Alcian Blue pH 1.0 for the detection of sulphated muco-substances and $\mathrm{pH} 2.5$ for detecting acidic mucosubstances; Schiff Periodic Acid (PAS) for neutral and acid (hydroxyl)

\footnotetext{
${ }^{1}$ Facultad de Medicina Veterinaria y Zootecnia, Universidad Peruana Cayetano Heredia, Lima, Perú

${ }^{2}$ Denver Zoological Foundation, EEUU

${ }^{3}$ E-mail: rgrandez@hotmail.com
}

Recibido: 22 de abril de 2017

Aceptado para publicación: 19 de noviembre de 2017 
mucopolysaccharides; Toluidine Blue for the identification of sulfated, carboxylate and phosphate acids, and to observe the presence of metachromacy, which indicates the presence of anionic or polyanionic acids; and Mallory's trichrome for the description of connective tissue. The skin samples had similarities with morphological characteristics of other amphibians described in previous studies: the dorsal and parotid regions have the greatest thickness of dermis and the two types of glands found denote being heterogeneous mucous and serous.

Key words: Telmatobius coleus; skin; glands; histology; histochemistry

\section{INTRODUCCIÓN}

Las ranas del género Telmatobius incluye 63 especies distribuidos desde el norte de los Andes ecuatorianos hasta el sur de los Andes chilenos y argentinos; la mayoría son acuáticos y habitan los arroyos y lagos entre los 1000 a 5200 m de altitud. En el Perú se han reportado 27 especies en una amplia variedad de hábitats que incluyen los valles secos de la vertiente de los Andes del Pacifico, los bosques secos alto andinos y los bosques húmedos de la vertiente amazónica (Ttito et al., 2016).

Se han descrito nuevas especies de Telmatobius en los páramos húmedos de Perú y Bolivia (Lavilla y Sandoval, 1999; De la Riva et al., 2005), en el altiplano de Chile y Bolivia (Sáez et al., 2014), en el norte de Chile (Formas et al., 2006) y en la vertiente de los Andes del Pacifico en Perú (Catenazzi et al., 2015). Asimismo, se vienen realizando trabajos abocados en determinar la taxonomía y la filogenia del género Telmatobius en base a estudios de secuenciamiento del ADN mitocondrial de estas especies (De la Riva $e t$ al., 2010).

Telmatobius culeus es una especie de anfibio endémico del lago Titicaca, ubicado en la frontera entre Perú y Bolivia, a una altitud de $3810 \mathrm{msnm}$. Está categorizada en Peligro Crítico (CR) por la Lista Roja de IUCN (2004) y el Decreto Supremo 0042014-MINAGRI. Los primeros trabajos so- bre la descripción de T. culeus los hizo Garman y Agassiz (1875). Esta especie ha sido objeto de diversos estudios anatómicos, fisiológicos y de comportamiento (Pérez, 1998).

T. culeus se caracteriza por su gran tamaño frente a otros anuros de la región, llegando a tener $160 \mathrm{~mm}$ en promedio de longitud (céfalo-caudal), pudiendo llegar a 180$200 \mathrm{~mm}$, con pesos de hasta $380 \mathrm{~g}$ (Ramos et $a l ., 2000)$. Presentan un escudo dorsal grueso con función hidrostática, tal como se ha reportado en la especie $T$. escomeli, que vive a una altitud de $4500 \mathrm{msnm}$ (Pérez, 2002).

Los dedos anteriores son libres y los posteriores semi-unidos; adaptaciones morfológicas y fisiológicas condicionadas por el ambiente que les permite compensar condiciones medioambientales de baja concentración de oxígeno del agua, bajas temperaturas $\left(<10^{\circ} \mathrm{C}\right)$ y cambios marcados de presión atmosférica (Fortúbel, 2007).

Este anfibio tiene la piel suave y holgada, en forma de un saco con pliegues desprendidos que cuelgan (Ramos, 2000). La piel es altamente vascularizada y plegada como respuesta evolutiva para una mejor difusión cutánea del oxígeno del agua, ya que es completamente acuática y respiran principalmente a través de la piel, que presenta modificaciones de vascularización descritos en relación con los hábitos acuáticos extremos en $T$. culeus (Pérez, 2002; Barrionuevo, 2017). 
La piel de los anfibios posee ciertas peculiaridades dependiendo de cada especie. La epidermis consiste en un estrato germinativo, formado por una única capa celular sobre la membrana basal, el estrato intermedio (normalmente de 3-8 células de grosor) y el estrato córneo superficial. La capa basal de la epidermis, estrato germinativo, está compuesta por células columnares o cuboidales, que migran superficialmente conformando el estrato espinoso y granuloso, y finalmente se queratinizan conformando el estrato córneo. El estrato córneo es una única capa de células que está queratinizado en los ejemplares adultos (Elias y Shapiro, 1957; Berger et al., 1998; Campbell et al., 2012).

La dermis está separada de la epidermis por una membrana basal. Se describen dos zonas: la externa denominada estrato esponjoso que se caracteriza por tejido conjuntivo areolar y contiene glándulas mucosas, glándulas serosas (granulares) y cromatóforos, y el estrato compacto que se encuentra inmediatamente debajo y es predominante colagenoso, pudiendo las glándulas serosas proyectarse dentro de esta zona. En los anuros, el integumento dorsal está ligeramente anclado al tejido subyacente, formando un espacio linfático subdermal llamado saco linfático. La piel de algunas especies contiene pequeñas estructuras óseas vascularizadas, ubicadas normalmente sobre el dorso y denominada como escudo dorsal (Mills y Prum, 1984). Asimismo, se ha descrito en la dermis de algunos anuros una capa calcificada entre los estratos corneo y esponjoso, denominada como capa de EberthKastschenko, cuya presencia ha sido asociada al modo de vida de los anuros (Barrionuevo, 2017).

Las glándulas dérmicas se ubican en el estrato esponjoso, están rodeadas de una cápsula de tejido conectivo colagenoso y poseen células mioepiteliales, que tienen ciertas características de las células del músculo liso, y sirven para una mayor contractibilidad. Sus contracciones ayudan a excretar las secreciones de los acinos hacia la superficie de la piel (Romero de Pérez y Ruiz-Carranza, 1996; Sinsch y Liehr, 2010). El moco producido es permeable al oxígeno y posee capacidad de osmoregulación. Muchas especies poseen una tercera capa de mucopolisacáridos dentro de la dermis, entre el estrato compacto y el estrato esponjoso, que se cree ayuda a prevenir la desecación en las especies terrestres (Elias y Shapiro, 1957).

En estudios con técnicas histoquímicas, como la tinción de ácido periódico de Schiff (PAS), se pudo identificar glándulas mucosas de la región ventral de la piel de Rana fuscigula, indicando la presencia de glicoproteínas en su contenido. Asimismo, muestras teñidas con Alcian Blue a diferentes $\mathrm{pH}$ evidenciaron la presencia de glicoproteínas ácidas en el contenido y glicoproteínas sulfatadas, determinando la naturaleza mixta de la glándula (Els y Henneberg, 1990). Asimismo, Sinsch y Liehr (2010) describieron en T carrillae dos tipos de glándulas mucosas PAS positivas y Alcian Green positivas (más grandes) o negativas (más pequeñas), indicando que el número de glándulas serosas fue muy bajo.

Adicionalmente, se dispone de estudios sobre la morfología de las glándulas exocrinas de anfibios (Mills y Prum, 1984), identificando a las glándulas mucosas en mucosas y seromucosas; sin embargo, estos tipos podrían representar diferentes estados de desarrollo del mismo tipo de glándula. Al respecto, Barrionuevo (2017) señala que las glándulas mucosas son más pequeñas que las serosas y se encuentran más superficiales distribuidas en el estrato esponjoso; en tanto que las serosas las clasifica en Tipo I (de gránulos pequeños) y Tipo II (de gránulos grandes) indicando que no parecen ser etapas diferentes de actividad de la misma glándula. De igual manera, Brunetti (2014) describe estos dos tipos principales de glándulas dérmicas en anuros, indicando que a pesar de poseer elementos comunes, ambos tipos glandulares presentan variaciones estructurales, ultraestructurales e histoquímicas. 
Existen poca información sobre la descripción histológica y las características histoquímicas de la piel en ranas sudamericanas. El objetivo del presente trabajo fue realizar una descripción morfométrica e histoquímica de la piel diferentes zonas del cuerpo del $T$. culeus para reconocer las características de la piel sana.

\section{Materiales y Métodos}

Las muestras fueron colectadas de 20 especímenes de T. culeus que fueron decomisados por la Administración Técnica y Forestal y de Fauna Silvestre de Lima en 2013, y que fueron entregados al Parque Zoológico Huachipa y alojados vivos en el Laboratorio de Vida Silvestre de la Facultad de Medicina Veterinaria y Zootecnia de la Universidad Peruana Cayetano Heredia (FAVEZUPCH), Lima, Perú. La mayoría de ejemplares murieron dentro de las primeras 48 horas de su recibo sin mostrar signos clínicos y lesiones macroscópicas, siendo almacenados en frascos de vidrio rotulados con formol al $10 \%$.

Para el estudio, se consideró como criterio de inclusión que todos los especímenes fueran de tamaño similar y que hubieran muerto sin alteraciones macroscópicas evidentes en la piel. Las muestras de piel fueron recolectadas de las regiones dorsal, parotídea, ventral, inguinal, palmar y plantar, en cortes de cerca de $1 \mathrm{~cm}^{2}$.

Las muestras fueron fijadas en formol al 10\% y siguieron el protocolo de la técnica histológica convencional hasta la obtención de bloque de parafina. Luego se realizaron cortes de $5 \mu \mathrm{m}$ de grosor con un micrótomo de rotación Leica.

Se aplicaron técnicas histoquímicas siguiendo el procedimiento utilizado en el Laboratorio de Histología y Patología de FAVEZ$\mathrm{UPCH}$.
- La tinción HE se empleó para describir las características morfológicas de la piel y la afinidad ácida o básica del contenido glandular (Montalvo, 2010).

- La tinción de Alcian Blue a pH 1.0 se empleó para la detección de mucosubstancias sulfatadas y a $\mathrm{pH} 2.5$ para detectar las mucosubstancias ácidas (Lev y Spicer, 1964).

- El ácido periódico de Schiff (PAS) se empleó para la identificación de mucosacáridos neutros (glucosa, manosa, fructuosa, galactosa) y ácidos sialicílicos (Montalvo, 2010).

- La tinción de Azul de Toloudina permitió identificar ácidos sulfatados, carboxilados y fosfatados; además de observar la presencia de metacromacia, que indica presencia de glicoproteínas componentes de mucosubstancias ácidas.

- El Tricrómico de Mallory permitió describir el tejido conectivo (Montalvo, 2010).

Para la descripción de las glándulas presentes en la piel, se denominó glándulas pequeñas a aquella que poseían dimensiones menores a $10 \mu \mathrm{m}$ de largo y ancho, y glándulas grandes a aquellas que superaban estas dimensiones.

Se obtuvieron registros fotomicrográfícos digitales de las observaciones realizadas utilizando el programa MoticImages Plus 2.0 con magnificación de $5 \mathrm{X}, 10 \mathrm{X}$ y $40 \mathrm{X}$, para realizar las descripciones morfológicas. Se registró la medida del grosor de la epidermis, dermis, el grosor total de la piel y las dimensiones de largo y ancho de todas las glándulas encontradas en cada región. Asimismo, de los resultados hallados con las tinciones histoquímicas especiales.

Los datos fueron consignados en una base Microsoft Excel y transferidos al programa Stata 12.0 para realizar la estadística descriptiva (promedios y desviaciones estándar). Se aplicó el análisis de varianza de un factor para determinar si existió diferencias significativas entre los promedios obtenidos. 


\section{Resultados}

La región dorsal presentó el mayor grosor de piel $(49.48 \pm 10.68 \mu \mathrm{m})$, seguida por la región parotídea $(46.19 \pm 16.05 \mu \mathrm{m})$. En la epidermis, la región palmar y la región ventral fueron las que presentaron el mayor espesor; mientras que en la dermis las regiones de mayor espesor fueron la parotídea y la dorsal (Cuadro 1).

Estructuralmente, los dos grupos de glándulas de la piel eran alveolares, conformadas por epitelio cuboidal simple. Se encontraron glándulas pequeñas en todas las regiones, cuyo ancho fue significativamente diferente en la región dorsal en comparación con las demás regiones $(\mathrm{p}<0.05)$. Asimismo, las glándulas de la región dorsal fueron más largas respecto a aquellas de las regiones inguinal y plantar. Además, se observó que las glándulas pequeñas de la región dorsal y parotídea presentaron mayores dimensiones que aquellas de otras regiones (Figura 1; Cuadro 2).

En el tejido dérmico solo se observaron glándulas grandes, exclusivamente en las regiones dorsal y parotídea; habiendo diferencia significativa en el ancho de estas glándu- las (dorsal: $30.42 \pm 10.38 \mu \mathrm{m}$; parotídea: 22.25 $\pm 3.23 \mu \mathrm{m} ; \mathrm{p}<0.05$ ), pero sin diferencias en longitud (dorsal: $25.06 \pm 12.65 \mu \mathrm{m}$; parotídea: $29.61 \pm 7.40 \mu \mathrm{m})$.

En toda la piel se encontró una conformación muy similar, formada por una epidermis con los estratos germinativo, intermedio y córneo. La dermis estuvo compuesta por una capa esponjosa, conformada por un tejido conectivo laxo con glándulas pequeñas, glándulas grandes y cromatóforos; y una capa compacta, más profunda conformada por tejido conectivo denso con una distribución de fibras colágenas, tanto longitudinales como transversales.

Con base a las observaciones de las láminas histológicas, al registro de las dimensiones y resultados de las técnicas histoquímicas (Cuadro 3), se elaboró la siguiente descripción de cada región de la piel de T. culeus.

\section{Región dorsal}

La epidermis mostró un estrato germinativo de capa simple, un estrato intermedio compuesto por unas cuatro capas de células epiteliales en promedio y la presencia

Cuadro 1. Dimensiones del espesor de la piel $(\mu \mathrm{m})$ (promedio y desviación estándar) de 20 especímenes Telmatobius culeus

\begin{tabular}{lccccccc}
\hline \multirow{2}{*}{ Región } & Muestras & \multicolumn{2}{c}{ Total $(\mu \mathrm{m})$} & \multicolumn{2}{c}{ Epidermis $(\mu \mathrm{m})$} & \multicolumn{2}{c}{ Dermis $(\mu \mathrm{m})$} \\
\cline { 3 - 8 } & $(\mathrm{n})$ & Media & D.S. & Media & D.S. & Media & D.S. \\
\hline Dorsal & 20 & 49.48 & 10.68 & 7.52 & 2.68 & 41.96 & 11.09 \\
Parotídea & 20 & 46.19 & 16.05 & 5.62 & 2.22 & 51.84 & 5.43 \\
Ventral & 20 & 29.64 & 6.25 & 9.32 & 4.11 & 20.34 & 6.69 \\
Palmar & 20 & 26.25 & 11.93 & 9.86 & 5.30 & 16.40 & 8.89 \\
Inguinal & 20 & 20.34 & 4.94 & 6.69 & 2.37 & 13.65 & 5.43 \\
Plantar & 20 & 19.37 & 9.64 & 7.44 & 4.99 & 26.83 & 13.72 \\
\hline Total & 120 & 31.88 & 15.76 & 7.74 & 4.11 & 28.50 & 17.61 \\
\hline
\end{tabular}


Cuadro 2. Dimensiones de las glándulas epiteliales pequeñas $(\mu \mathrm{m})$ en 20 especímenes Telmatobius culeus

\begin{tabular}{lcccc}
\hline \multirow{2}{*}{ Región } & \multicolumn{2}{c}{$\begin{array}{c}\text { Ancho de la glándula } \\
(\mu \mathrm{m})\end{array}$} & \multicolumn{2}{c}{$\begin{array}{c}\text { Largo de glándula } \\
(\mu \mathrm{m})\end{array}$} \\
\cline { 2 - 5 } & Media & $\begin{array}{c}\text { Desviación } \\
\text { estándar }\end{array}$ & Media & $\begin{array}{c}\text { Desviación } \\
\text { estándar }\end{array}$ \\
\hline Dorsal & $8.66^{\mathrm{a}}$ & 7.33 & $9.97^{\mathrm{a}}$ & 1.80 \\
Inguinal & $5.03^{\mathrm{b}}$ & 1.34 & $6.56^{\mathrm{b}}$ & 1.35 \\
Parotídea & $6.97^{\mathrm{a}, \mathrm{b}}$ & 1.09 & $8.73^{\mathrm{a}, \mathrm{b}}$ & 1.13 \\
Plantar & $4.81^{\mathrm{b}}$ & 1.46 & $6.33^{\mathrm{b}}$ & 1.52 \\
Palmar & $6.31^{\mathrm{b}}$ & 1.68 & $8.21^{\mathrm{a}, \mathrm{b}}$ & 2.01 \\
Ventral & $6.27^{\mathrm{b}}$ & 1.11 & $8.26^{\mathrm{a}, \mathrm{b}}$ & 0.86 \\
\hline
\end{tabular}

a,b Superíndices diferentes dentro de columnas indican diferencia estadística $(p<0.05)$

Cuadro 3. Resultado a las técnicas histoquímicas en glándulas pequeñas y grandes de piel en 20 especímenes Telmatobius culeus

\begin{tabular}{|c|c|c|c|c|c|c|c|c|c|c|c|c|}
\hline \multirow[t]{3}{*}{ Región } & \multicolumn{2}{|c|}{$\begin{array}{c}\text { Tinción } \\
\text { HE }\end{array}$} & \multicolumn{2}{|c|}{$\begin{array}{l}\text { Tinción } \\
\text { PAS }\end{array}$} & \multicolumn{4}{|c|}{ Tinción Alcian Blue } & \multicolumn{2}{|c|}{$\begin{array}{l}\text { Tinción Azul } \\
\text { de Toloudina }\end{array}$} & \multicolumn{2}{|c|}{$\begin{array}{l}\text { Tricrómico de } \\
\text { Mallory }\end{array}$} \\
\hline & GG & GP & GG & GP & GG & GG & GP & GP & GG & GP & $\mathrm{C}$ & Q \\
\hline & & & & & $\begin{array}{c}\mathrm{pH} \\
1\end{array}$ & $\begin{array}{l}\mathrm{pH} \\
2.5\end{array}$ & $\begin{array}{c}\mathrm{pH} \\
1\end{array}$ & $\begin{array}{l}\mathrm{pH} \\
2.5\end{array}$ & & & & \\
\hline Dorsal & $\mathrm{E}$ & B & $(+)$ & $(-)$ & $(+)$ & $(+)$ & $(-)$ & $(-)$ & $(+)$ & $(+++) /(-)$ & $(++)$ & $(+++)$ \\
\hline Ventral & & B & -- & $(-)$ & -- & -- & $(-)$ & $(-)$ & -- & $(++) /(-)$ & $(+++)$ & $(+)$ \\
\hline Parotídea & E & B & $(+)$ & $(-)$ & $(+)$ & $(+)$ & $(-)$ & $(-)$ & $(+)$ & $(++) /(-)$ & $(+++)$ & $(+++)$ \\
\hline Inguinal & & B & -- & $(-)$ & -- & -- & $(-)$ & $(-)$ & -- & $(+++) /(-)$ & $(++)$ & $(+)$ \\
\hline Palmar & & B & -- & $(-)$ & -- & -- & $(-)$ & $(-)$ & -- & $(+++) /(-)$ & $(++)$ & $(+)$ \\
\hline Plantar & & B & -- & $(-)$ & -- & -- & $(-)$ & $(-)$ & -- & $(+++) /(-)$ & $(++)$ & $(++)$ \\
\hline
\end{tabular}

GG: glándulas grandes; GP: glándulas pequeñas; C: colágeno; Q: queratina

E: eosinofilica; B: basofílica, (+) positivo; (-) negativo; (--) ausencia

de una capa fina de estrato córneo queratinizado. La dermis presentó una capa esponjosa de tejido conectivo laxo en donde se encontraron abundantes cromatóforos, glándulas pequeñas y glándulas grandes; en tanto que en la dermis profunda se observó una capa compacta de fibras colágenas y fibras elásticas (Figura 1A).
Histoquímicamente, se identificaron tres poblaciones de glándulas. Un grupo formado por glándulas grandes eosinofílicas, con afinidad a la tinción de PAS, a la de Alcian Blue, tanto a $\mathrm{pH} 1$ como a 2.5, y al azul de Tolouidina, lo que demostró la presencia de mucopolisacáridos neutros, sulfatados y no sulfatados; polisacáridos sulfatados, ácidos y 
carboxilados; así como la presencia de polisacáridos sulfatados, carboxilados $\mathrm{y}$ fosfatados, respectivamente. Las glándulas pequeñas se dividieron en dos grupos: las positivas solo a azul de Tolouidina y otro grupo de glándulas pequeñas negativas a todas las tinciones aplicadas.

\section{Región parotídea}

La epidermis presentó un estrato germinativo de una capa, un estrato intermedio con 5-8 capas y un estrato corneo con una única capa discontinua de queratina. A nivel de la dermis, en la capa esponjosa se encontraron algunos cromatóforos, así como glándulas grandes y pequeñas (Figura 1B).

Las glándulas grandes fueron eosinofílicas, demostrando la presencia de mucopolisacáridos neutros, sulfatados y no sulfatado, así como polisacáridos sulfatados, ácidos, fosfatados y carboxilados. Las glándulas pequeñas fueron basofilicas, demostrando la presencia de mucopolisacáridos sulfatados, fosfatados y carboxilados; además, en la capa esponjosa de la dermis se encontró regular cantidad de células cebadas con granulaciones metacromáticas.

\section{Región ventral}

La epidermis estaba conformada por un estrato germinativo de una capa, un estrato intermedio con 5-7 capas de células, y un estrato córneo formado por una capa discontinua de queratina (Figura 1C). En la capa esponjosa de la dermis se observaron solo glándulas pequeñas basofílicas, demostrando mucopolisacáridos sulfatados ácidos y carboxilados. También se identificaron glándulas pequeñas basofílicas, demostrando la presencia de mucopolisacáridos sulfatados, fosfatados y carboxilados. Asimismo, se observó tejido conectivo laxo alrededor de cada glándula, además de una discreta cantidad de cromatóforos.

\section{Región inguinal}

La epidermis presentó un estrato germinativo de una capa, un estrato intermedio con 5 a 7 capas y una capa córnea queratinizada (Figura 1D). En el estrato esponjoso de la dermis se encontraron escasos cromatóforos y numerosas glándulas pequeñas basofílicas, demostrando la presencia de mucopolisacáridos sulfatados, fosfatados y carboxilados.

\section{Región palmar}

La epidermis presentó un estrato germinativo de una capa, un estrato intermedio con 5-12 capas de células en promedio con uniones celulares prominentes, y un estrato córneo con doble capa de células queratinizadas. Entre el estrato intermedio y el córneo se evidenció un estrato lúcido muy tenue (Figura 1E). En el estrato esponjoso de la dermis superficial se observaron algunos cromatóforos y glándulas pequeñas con poco contenido basofílico, demostrando la presencia de mucopolisacáridos sulfatados, fosfatados y carboxilados. La dermis profunda estuvo conformada por un tejido conectivo compacto.

\section{Región plantar}

La epidermis fue gruesa, con un estrato germinativo de capa simple, un estrato intermedio con 8-10 capas. Al igual que en la región palmar, se encontró un estrato lúcido muy delgado y un estrato córneo con un doble capa de células queratinizadas (Figura 1F). En la capa esponjosa de la dermis se observaron algunos cromatóforos y glándulas pequeñas con escaso contenido de mucopolisacáridos sulfatados, fosfatados y carboxilados. 


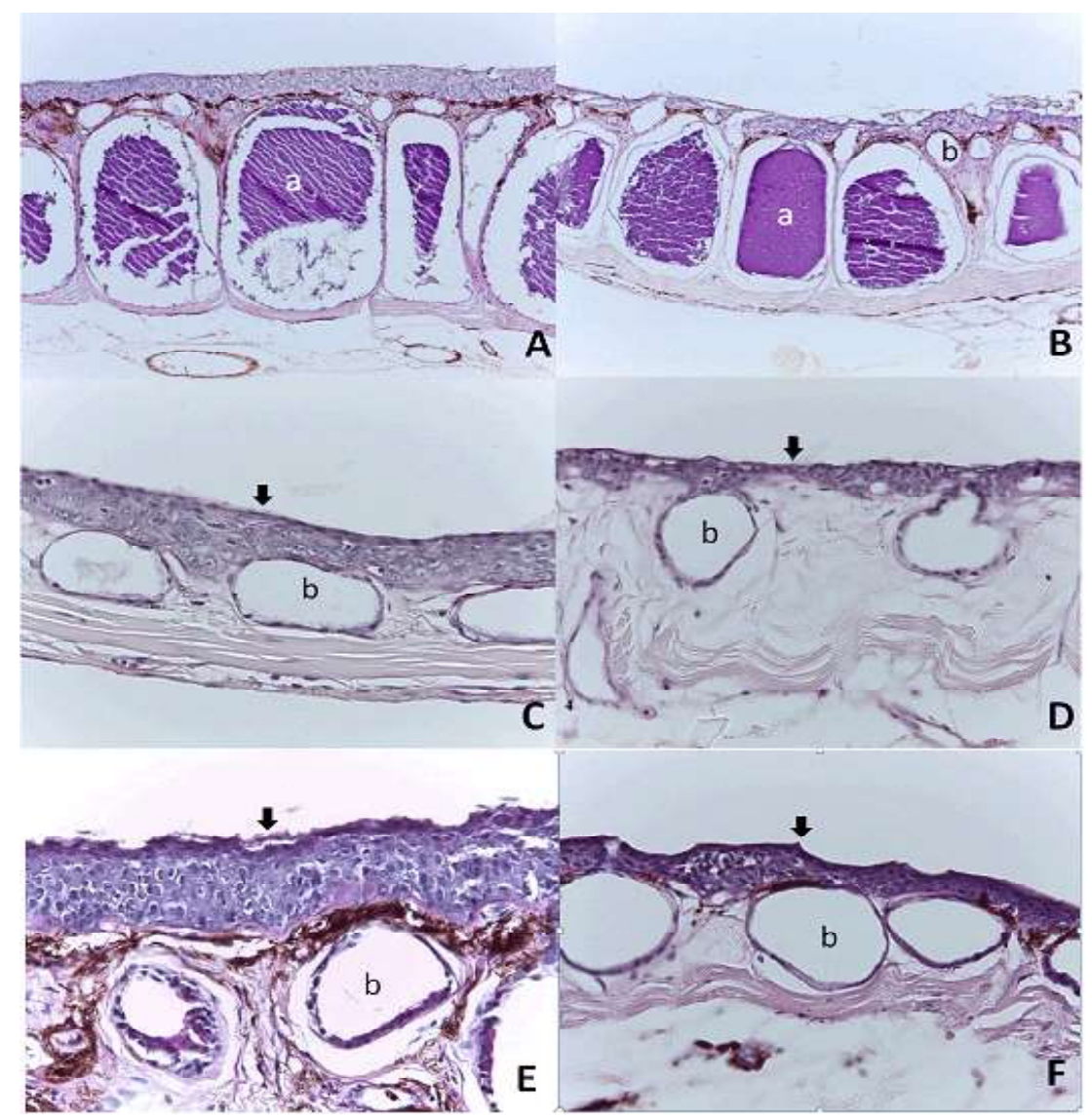

Figura 1. Imágenes microscópicas de la región epitelial dorsal (A) y parotídea (B) de Telmatobius culeus mostrando las glándulas grandes en la dermis, que contienen una secreción PAS positiva (a), las glándulas pequeñas (b) y los melanóforos de color marrón oscuro. Tinción PAS, 40X. Imágenes C, D, E y F muestran la región ventral, inguinal, palmar y plantar, respectivamente. Las flechas señalan la epidermis con su estrato córneo; la dermis solo muestra glándulas pequeñas (b) y los melanóforos solo se observan en la dermis de las regiones palmar y plantar. Tinción $\mathrm{HE}, 100 \mathrm{X}$

\section{Discusión}

En el presente estudio se observó en $T$. culeus un mayor grosor de la piel en la región dorsal y parotídea con relación a la ventral, similar a los hallazgos de García et al. (2011) en su estudio de caracterización histomorfológica de Leptodactylus del grupo fuscus, y de Romero de Pérez y RuizCarranza (1996) en las especies Hyla alytolylax e Hyla sp, indicando que el grosor total de la piel dorsal es mayor que la ventral. Estos estudios demuestran variacio- nes en el espesor de la epidermis, lo cual se debe más al aumento del volumen de las células epidérmicas que al aumento del número de capas; hallazgo similar al presente estudio donde la variación de capas, independiente del grosor de la piel, fue entre 4 a 8 , a excepción de las regiones palmar y plantar que alcanzaron las 12 capas.

Igualmente se describe en este estudio la presencia de un tenue estrato lúcido en la piel de la región palmar y plantar de T. culeus, como se observa en las almohadillas plantares o la palma y planta de las extremidades de 
algunos mamíferos. Estas zonas poseen epidermis gruesas, generalmente desprovistas de pelo y de alto contacto físico, en la que se observa gran cantidad de capas de células epiteliales queratinizadas en el estrato córneo (Banks, 1996). Asimismo, Elías y Shapiro (1957) describieron la presencia de un estrato lúcido debajo de las microscópicas verrugas corneas presente en la piel dorsal del Bufo americanus.

Duellman y Trueb (1986) han descrito en diversas especies de ranas la presencia de un escudo dorsal, osteodermo, conformada por placas óseas dispuestas en la epidermis, que puede llegar en algunas especies hasta $10 \mathrm{~mm}$ de espesor. Ramos (2000) indica que estas poseen función hidrostática y de compensación metabólica; sin embargo, en este estudio se determinó la ausencia de esta estructura en $T$. culeus, evidenciando que esta estructura no es requerida por esta especie para sobrevivir en las condiciones de poca disponibilidad de oxígeno del agua, bajas temperaturas y cambios marcados de presión.

Asimismo, García et al. (2011) describen en la dermis de Leptodactylus la presencia de la capa Eberth-Kastschenko como una capa calcificada entre los estratos compacto y laxo, indicando que el espesor de esta capa varía entre especies, siendo significativamente más gruesa en la región dorsal. En el presente estudio se determinó la ausencia de esta capa en T. culeus; información que concuerda con el estudio de Barrionuevo (2017) quien describe la presencia de esta capa en todas las especies del género Telmatobius, a excepción de $T$. atacamensis, donde se observa esporádicamente y de T. culeus en la que está ausente.

La dermis mostró mayor grosor en las regiones dorsal y parotídea debido a que son las únicas que poseen, a la vez, glándulas grandes y pequeñas, ya que el resto de regiones solo posee glándulas pequeñas ubicadas en la capa esponjosa de la dermis. También se encontró una mayor cantidad de tejido conjuntivo en las regiones dorsal y parotídeas, ya que estructuralmente este tejido brinda soporte a las glándulas presentes en ellas. Estos resultados concuerdan con lo descrito por García et al. (2011) quienes indican que el grosor de la dermis laxa, estrato esponjoso, es mayor en las zonas de piel que poseen glándulas que en aquellas que no la presen$\tan$.

En referencia a las glándulas presentes en la piel del género Telmatobius, Barrionuevo (2017) describe dos tipos de glándulas serosas, con distintos tipos de gránulos clasificándolas en tipo I y II, indicando su presencia en todas la especies del género, a excepción del tipo II en $T$. boliviensis y $T$. culeus; hallazgo que concuerda con las glándulas pequeñas descritas en este estudio, observándose un grupo que fue negativo a todas las técnicas histoquímicas empleadas, $\mathrm{y}$ que corresponderían a una etapa inmadura.

Respecto a las glándulas mucosas en ranas, Els y Henneberg (1990) en Rana fuscigula, Moreno-Gómez et al. (2014) en Phyllobates bicolor y Barrionuevo (2017) en especies del género Telmatobius las describen como glándulas más pequeñas o de similar tamaño a las serosas, distribuidas en todas las regiones corporales, dando reacción positiva a la presencia de mucopoliscáridos. Asimismo, De Pérez y Ruíz (1985) describieron en la piel del Cryptobratachus la presencia de dos tipos de glándulas mucosas diferenciables histológica e histoquímicamente.

En el presente estudio se encontró un solo tipo de glándula mucosa con reacción histoquímica principalmente a mucopolisacáridos, denominadas glándulas grandes por su tamaño mucho mayor a las serosas y a las descritas en estudios previos en otras especies de ranas. Estas glándulas están presentes únicamente en las regiones dorsal y parotídea del T. culeus, pudiendo indicar que su función es la producción de moco en la piel que permite el intercambio iónico y permeabilidad de los gases en ambientes con 
poca disponibilidad de oxígeno y bajas temperaturas como se da en el ambiente natural de esta especie.

\section{Conclusiones}

- La región dorsal y la región parotídea de la piel de Telmatobius culeus presentan glándulas grandes y pequeñas, por lo cual estas regiones tienen el mayor espesor de la dermis y el mayor espesor total de la piel que otras regiones corporales.

- Telmatobius culeus presenta mayor grosor de la epidermis en las regiones palmar y ventral en relación a otras regiones corporales.

- El tipo de secreción glandular en $T$. culeus fue de naturaleza heterogénea, indicando que estas glándulas pueden ser serosas y mucosas; además que se pueden encontrar en diferentes estados de maduración morfológica.

\section{Literatura Citada}

1. Banks W. 1996. Histología veterinaria aplicada. Madrid, España: Ed Manual Moderno. $750 \mathrm{p}$.

2. Barrionuevo JS. 2017. Skin structure variation in water of the genus Telmatobius (Anura Telmatobiidae). Salamandra 53: 183-192.

3. Berger L, Speare R, Daszak P, Green $D E$, Cunningham AA, Goggin CL, Slocombe $R$, et al. 1998. Chytridiomycosis causes amphibian mortality associated with population declines in the rain forest of Australia and Central America. Proc Natl Acad Sci 95: 9031-9036.

4. Brunetti AE. 2014. Comunicación química en anuros: una perspectiva integral a partir de aspectos comportamentales, morfológicos y químicos en dos especies de Hypsiboas (Amphibia: Anura: Hylidae). Tesis Doctoral. Argentina: Univ. de Buenos Aires. 291 p.
5. Campbell CR, Voyles J, Cook D, Dinudom A. 2012. Frog skin epithelium: electrolyte transport and chytridiomycosis. Int J Biochem Cell Biol 44: 431434. doi: 10.1016/j.biocel.2011.12.002

6. Catenazzi A, Vargas V, Lehr E. 2015. A new species of Telmatobius (Amphibia, Anura, Telmatobiidae) from the Pacific slopes of the Andes, Peru. ZooKeys 480: 81-95. doi: 10.3897/ zookeys. 480.8578

7. De La Riva I, Aparicio J, Ríos JN. 2005. New species of Teliatobius (Arnura: Leptodactylidae) from humid paramo of Peru and Bolivia. J Herpetol 39: 409-416. doi: 10.1670/178-84A.1

8. De la Riva, García-París M, ParraOlea G. 2010. Systematics of Bolivian frogs of the genus Telmatobius (Anura, Ceratophryidae) based on mtDNA sequences. Syst Biodivers 8: 49-61. doi: 10.1080/14772000903526454

9. De Pérez G, Ruiz PM. 1985. Ultraestructura e histoquímica de dos tipos de glándulas mucosas de la piel de Cryptobatrachus (Amphibia, Anura). Caldasia 14: 251-264.

10. Duellman W, Trueb L. 1986. Integumentary, sensory, and visceral systems. In: Biology of amphibians. USA: McGraw-Hill. p 367-414.

11. Elias H, Shapiro J. 1957. Histology of the skin of some toads and frogs. American Museum Novitates 1819.27 p.

12. Els WJ, Henneberg R. 1990. Histological features and histochemistry of the mucous glands in ventral skin of the frog (Rana fuscigula). Histol Hitopathol 5: 343-348.

13. Fontúrbel F, Richard E. 2004. Propuesta de producción sostenible e industrialización del Telmatobius culeus (Anura, Leptodactylidae): hacia la conservación de especies endémicas que apoyen el desarrollo sostenible en el lago Huiñaimarca (Bolivia). En: Richard E, Fontúrbel $\mathrm{F}$ (eds). Aportes al conocimiento del manejo de vida silvestre en Argentina y Bolivia. La Paz. Bolivia: Ed Publicaciones Integrales. $32 \mathrm{p}$. 
14. Formas JR, Cuevas CC, Nuñez JJ. 2006. A new species of Telmatobws (anura: leptodactyudae) from northern Chile. Herpetologica 62: 173-183.

15. García GF, Cruz PI, Mangione S. 2011. Caracterización histomorfológica de la piel de especies de Leptodactylus del grupo fuscus (Anura: Leptodacty-lidae), destacando la capa de Eberth-Katschenko. Acta Zoool Lilloana 55: 33-43.

16. Garman SW, Agassiz AE. 1875. Exploration of Lake Titicaca. I. Fishes and reptiles. Bull Museum of Comparative Zoology 3: 273-278.

17. [IUCN] International Union for Conservation of Nature and Natural Resources. 2004. The IUCN Red List of Threatened Species. [Internet]. Available in: http://www.iucnredlist.org

18. Lavilla EO, Sandoval PE. 1999. A new Bolivian species of the genus Telmatobius (Anura: Leptodactylidae) with a humeral spine. Amphibia-Reptilia 20: 55-64.

19. Lev R, Spicer SS. 1964. Specific staining of sulphate groups with Alcian Blue at low $\mathrm{pH}$. J Histochem Cytochem 12: 309. doi: 10.1177/12.4.309

20. Mills JW, Prum BE. 1984. Morphology of the exocrine glands of the frog skin. Am J Anat 171: 91-106. doi: 10.1002/ aja.1001710108

21. Montalvo C. 2010. Técnica histológica. [Internet]. Disponible en: http:// www.geocities.ws/medicina_unam/ histologia/tecnica/index.html

22. Moreno-Gómez F, Duque T, Fierro L, Arango J, Peckham X, AsencioSantofimio $H$. 2014. Histological description of the skin glands of Phyllobates bicolor (Anura: Dendrobatidae) using three staining techniques. Int $\mathrm{J}$ Morphol 32: 882-888.

23. Nakayima T, Yasuhara T .1977. A new mast cell degranulating peptide, granuliberin- $\mathrm{R}$ in the frog (Rana rugosa) skin. Chem Pharm Bull 25: 24642465. doi: $10.1248 / \mathrm{cpb} .25 .2464$
24. Pérez ME. 1998. Dieta y ciclo gametogeìnico anual de Telmatobius culeus (Anura, Leptodactylidae) en el Lago Titicaca (Huiñaimarca). Tesis de Maestría. La Paz, Bolivia: Univ Mayor de San Andreìs. $140 \mathrm{p}$.

25. Pérez ME. 2002. Evaluación de la población de la rana gigante en Bolivia (Informe técnico). Bolivia: Autoridad Binacional del Lago Titicaca-PNUD. 112 p.

26. Ramos LD. 2000. Evaluación de la información disponible de Suri, Picasa, rana gigante del Lago. Proyecto de conservación de la biodiversidad en la cuenca del Sistema Titicaca, Desaguadero, Poopo, Salar de Coipasa (TDPS). UNAPUNO.

27. Romero de Pérez G, Ruiz-Carranza PM. 1996. Histología, histoquímica y estructura fina de la glándula mentoniana de dos especies de Hyla (grupo bogotensis) y del antebrazo de Phrynopus adenobatrachius. Rev Acad Colomb Ciencias Exactas Físicas Naturales 20: 575-584.

28. Sáez PA, Fibla P, Correa C, Sallaberry M, Salinas H, Veloso A, Mella J, Iturra P, Méndez MA. 2014. A new endemic lineage of the Andean frog genus Telmatobius (Anura, Telmatobiidae) from the western slopes of the central Andes. Zool J Linn Soc 171: 769-782. doi: 10.1111/zoj.12152

29. Sinsch U, Lehr E. 2010. Geographical variation in the high Andean frog Telmatobius carrillae Morales, 1988 (Ceratophryidae, Telmatobiinae): size, skin texture, and coloration. J Herpetol 44: 495-505. doi: 10.1670/09-081.1

30. Ttito A, Landauro CZ, Venegas PJ, De la Riva I, Chaparro JC. 2016. A new species of Telmatobius Wiegmann, 1834, from the eastern Cordillera Central of the Andes, Perú (Anura: Telmatobiidae), with description of its tadpole, and range extension of $T$. mendelsoni De la Riva et al., 2012. Ann Carnegie Mus 83: 255-268. doi: 10.2992/ 007.083.0402 